\title{
DIFERENÇAS DE GÉNERO NO CONFLITO TRABALHO- -FAMÍLIA: UM ESTUDO COM FAMÍLIAS PORTUGUESAS DE DUPLO-EMPREGO COM FILHOS EM IDADE PRÉ-ESCOLAR ${ }^{1}$
}

\author{
Marisa Matias ${ }^{2}$ \\ Cláudia Andrade \\ Anne Marie Fontaine
}

Resumo: Portugal apresenta uma crescente participação feminina no mercado de trabalho, levando a que o modelo familiar de um único elemento a trabalhar fora de casa tenha perdido expressão. Actualmente, as famílias de duplo-emprego ultrapassam em número as famílias com um único emprego, pelo que homens e mulheres debatem-se com as novas exigências do seu trabalho e da sua família. Assim, as responsabilidades do trabalho profissional, tarefas domésticas e cuidado dos filhos não se confinam mais à divisão tradicional dos papéis de género. Deste modo, uma relação conflitual entre as duas esferas é cada vez mais evidente. Neste estudo evidenciam-se as vivências de conflito profissional e familiar de homens e mulheres de famílias de duplo-emprego $(\mathrm{n}=492)$ com filhos em idade pré-escolar. Os resultados apontam que o conflito trabalho-família é distinto do conflito família-trabalho e que este processo é particularmente distinto para homens e mulheres. Os antecedentes de cada tipo de conflito são também explorados em função do género.

Palavras-chave: conflito trabalho-família; conflito família-trabalho; famílias de duplo-emprego; género

Gender differences in work-family conflict: a study with Portuguese dual-earner families with toddlers (Abstract): Portugal has one of the highest rates of female employment in Europe. Therefore the male breadwinner model has become less prevalent. Nowadays, dual-earner families outnumber single earner families. Consequently, traditional gender roles seem to be outdated and men and women have to deal with new demands both in the work and family spheres. In this context, conflict relations between work and family occur. This study aims to analyse the experiences of inter-role conflict in men and women from dual-earner families

\footnotetext{
${ }^{1}$ Nota: Artigo revisto e aceite para publicação sob a responsabilidade da anterior direcção da revista Psicologia.

2 Centro de Psicologia Diferencial - Faculdade de Psicologia e Ciências da Educação Universidade do Porto.
} 
with pre-school children $(n=492)$. Results showed that work to family and family to work conflict have different antecedents and that men and women deal and experience it differently. The antecedents of each type of conflict are also explored according to gender.

Key-words: Work-to-family conflict, family-to-work conflict; dual-earner families; gender

\section{Introdução}

A presença generalizada das mulheres no campo laboral que se tem verificado nas últimas décadas tem consequências directas na vida familiar, rompendo, parcialmente, com o modelo de complementaridade entre homens e mulheres. Este modelo assentava na diferenciação de tarefas entre os dois sexos, segundo o qual o trabalho remunerado era da responsabilidade masculina e o trabalho não remunerado, isto é, familiar, era da responsabilidade feminina. Este facto criou novos desafios e dilemas para os indivíduos e para as famílias, introduzindo alterações nos papéis de género, tanto no domínio profissional como no familiar (Wall, 2005).

O estudo da integração harmoniosa das relações trabalho-família tornou-se assim particularmente relevante, dando origem a um conjunto de quadros de análise conceptual e de estudos empíricos. Estes estudos, salientam, em geral, que as dificuldades sentidas na articulação entre papéis profissionais e familiares são mais frequentes e intensas nas mulheres (Zimmerman, Haddock, Current, \& Ziemba, 2003). Se actualmente, e para o contexto nacional, as responsabilidades relativas ao trabalho profissional parecem ser partilhadas por homens e mulheres, o mesmo não acontece no domínio familiar: as tarefas domésticas e de cuidado dos filhos continuam a ser maioritariamente da responsabilidade feminina (Fontaine, Andrade, Matias, Gato, \& Mendonça 2007; Torres, 2004; Wall, 2005). Esta realidade coloca obstáculos à conciliação dos dois domínios para as mulheres, podendo mesmo criar um conflito entre papéis profissionais e familiares. Apesar desta realidade, particularmente penalizadora para as mulheres ter sido documentada por alguns estudos, as mudanças nos papéis de género estimulam também um maior investimento dos homens na vida familiar, nomeadamente ao nível dos cuidados aos filhos (Coltrane, 2000), podendo, por conseguinte, também para estes, surgir um quadro de conflito de papéis.

É nesta linha de análise das diferenças de género que se situa o presente trabalho. Pretende-se caracterizar os níveis de conflito de papéis vividos por famílias de duplo-emprego com filhos em idade pré-escolar, procu- 
rando-se ainda evidenciar alguns dos seus antecedentes ao nível profissional e familiar.

\section{Conflito trabalho-família e família-trabalho}

Apesar do exercício do papel profissional ser indispensável à manutenção económica da família, a gestão das obrigações familiares e profissionais não está isenta de conflito. Segundo Greenhaus \& Beutell (1985), os indivíduos possuem uma quantidade limitada de recursos psicológicos e fisiológicos em termos de tempo, atenção e energia, o que torna difícil fazer face às diferentes exigências de cada papel, podendo surgir o conflito entre papéis. Mais especificamente, Greenhaus \& Beutell (1985), evidenciaram três formas de conflito trabalho-família: conflito baseado no tempo, conflito baseado na tensão e conflito baseado no comportamento. O conflito baseado no tempo implica que os múltiplos papéis que o indivíduo desempenha competem entre si em termos de tempo, ou seja, o tempo dispendido num papel interfere com a disponibilidade de tempo para o outro papel. O conflito baseado na tensão implica que a pressão criada no âmbito do desempenho de um dos papéis dificulta o cumprimento das exigências do outro papel. Por exemplo, as pressões para o desempenho, as pressões psicológicas e os problemas interpessoais levam a irritabilidade, fadiga ou apatia, o que afecta, necessariamente, o desempenho do outro papel. Por fim, o conflito baseado no comportamento corresponde a padrões comportamentais específicos de um determinado papel que podem ser incompatíveis com as expectativas comportamentais de outro papel. Por exemplo, um estilo de comportamento no desempenho do papel profissional que é pautado por poder, autoridade e impessoalidade pode ser incompatível com comportamentos esperados na esfera familiar, que exigem afectuosidade, carinho e relações próximas.

A maioria dos estudos sobre o conflito de papéis tem centrado a sua atenção na transferência de atitudes ou estados de humor negativos de um domínio para o outro, bem como nos efeitos da competição na utilização do tempo disponível para o exercício de cada papel, isto é, no conflito baseado na tensão e no tempo (Edwards \& Rothbard, 2000). Greenhaus \& Beutell (1985), assumem também uma conceptualização bidirecional do conflito inter-papéis defendendo a distinção entre a interferência do papel profisssional no papel familiar e a interferência do papel familiar no papel profissional. O conflito entre o papel profissional e o papel familiar ocorre quando a participação ou as emoções associadas à actividade profissional têm um efeito negativo no exercício do papel familiar. Pelo contrário, a interferência do papel familiar no papel profissional ocorre quando a participação numa actividade familiar colide com a participação numa actividade profissional 
(Greenhaus \& Powell, 2003). De um modo geral, as pressões profissionais têm sido identificadas como uma fonte poderosa de conflito trabalho-família, enquanto que as pressões familiares estão mais fortemente relacionadas com o conflito família-trabalho (Frone, Russel, \& Cooper, 1992a; Frone, Yardley \& Markel, 1997).

No entanto, a investigação tem-se debruçado mais sobre a influência negativa da esfera profissional no desempenho do papel familiar do que o oposto (Frone et al., 1992a; Frone et al., 1997; Greenhaus \& Beutell, 1985; O'Neil, Greenberger, \& Marks, 1994). Os autores justificam esta tendência pelo facto das interferências do domínio profissional no domínio familiar serem as mais frequentes (Frone et al., 1992a; Grzywacz \& Bass, 2003; Gutek, Searle \& Klepa 1991), possivelmente devido à permeabilidade assimétrica das fronteiras entre o domínio familiar e profissional (Pleck, 1977 in Frone, Russel, \& Cooper, 1992b). Isto poderá significar que é mais tolerado que o domínio familiar seja influenciado pelas exigências profissionais, do que o domínio profissional pelas exigências familiares. Tal tolerância é reforçada pelo facto das tarefas de âmbito familiar serem mais flexíveis do que as tarefas do domínio profissional. Com efeito, as tarefas familiares podem ser efectuadas de acordo com horários mais flexíveis ou mesmo não chegarem a ser cumpridas integralmente pelos próprios (por exemplo, a limpeza ou o cuidado das roupas). Adicionalmente, a produtividade que é exigida aos trabalhadores no seu local de trabalho implica uma limitação de qualquer interrupção nestas tarefas.

De referir, contudo, diversos estudos que apontam para que os dois tipos de interferência entre papéis sejam relatados por uma parte significativa dos indivíduos, o que parece evidenciar que os domínios profissional e familiar constituem sistemas em interacção recíprocos e dinâmicos (Crouter, 1984 in Marshall \& Barnett, 1993). Neste sentido, parece importante comparar, não apenas a intensidade dos dois tipos de conflitos num mesmo grupo de indivíduos, mas também analisar os seus possíveis antecedentes.

\section{Diferenças de género nos estudos sobre o conflito de papéis}

Apesar do papel evidente que as ideologias de género têm tido na divisão do trabalho familiar e profissional, a análise dos efeitos moderadores do género na relação trabalho-família não têm sido alvo de muita atenção por parte da literatura (Parasuraman \& Greenhaus, 2002). Apesar das mudanças sociais que afectam os papéis de género, parece que a diferenciação em função do sexo do exercício dos papéis profissionais e familiares é ainda vista como uma base legítima e ideologicamente aceitável para a distribuição dos direitos, poder e responsabilidades (Franks, 1999; Hughes \& 
Galinsky, 1988; Major, 1993; Poeschl, 2000). Embora, nos contextos de trabalho actuais, a mulher exerça a sua actividade em quase todos os sectores de actividade e possua horários de trabalho e exigências, na maioria dos casos, idênticas às dos homens (Cabral-Cardoso, 2003; Gianakos, 2000; Gutek et al., 1991; Peterson \& Gerson, 1993), não se observa uma repartição equivalente das tarefas familiares, entre homens e mulheres. Ou seja, o aumento da participação das mulheres no mercado de trabalho, não tem tido correspondência num aumento dos homens na participação no trabalho não pago (Perista, 2002; Stier \& Lewin-Epstein, 2000; Torres, 2004).

Esta divisão assimétrica das responsabilidades familiares parece suscitar sentimentos de sobrecarga por parte das mulheres e tornar consequentemente, o conflito de papéis, mais evidente nas mulheres do que nos homens (Almeida, Wethington \& Chandler, 1999; Ingersoll-Dayton, Neal, \& Hammer, 2001).

Numa análise detalhada da vida familiar, facilmente se observa que as mulheres efectuam a maioria das tarefas ligadas à casa e aos filhos, funções definidas culturalmente como femininas. Esta constatação parece ser transversal a diferentes culturas e níveis sócio-económicos, apesar de também serem visíveis variações no envolvimento dos homens no trabalho doméstico (Fontaine, et al., 2007; Rachlin, 1987; Stier \& Lewin-Epstein, 2000).

Em Portugal a participação feminina no mercado de trabalho pode ser considerada elevada à escala europeia: $61.3 \%$ das mulheres trabalham fora de casa, constituindo 46,9\% da força de trabalho nacional (INE, 2002; 2004). Assim, as mulheres contribuem de forma significativa para o sustento económico da família, fazendo com que o modelo de casais de duplo-emprego seja o mais frequente na sociedade portuguesa (Vicente, 1998; Wall, 2005). O estudo de Perista (2002) sobre os usos do tempo demonstra que as mulheres portuguesas, independentemente do seu estatuto profissional, desempenham a maior parte das tarefas familiares e domésticas. Neste sentido, Portugal conjuga valores tradicionais relacionados com o papel da mulher na família e na educação dos filhos (Wall, 2005), com a valorização da actividade profissional feminina, característica de uma perspectiva mais igualitária quanto à participação da mulher no domínio social e profissional (Torres, 2004). Apesar de, em Portugal, os constrangimentos económicos serem ainda um factor preponderante, não explicam, por si só, a participação massiva das mulheres no mercado de trabalho. De facto, na ausência de tais constrangimentos, estas não pretendem abdicar da sua vida profissional (Torres, 2004).

Deste modo pensamos encontrar uma percepção de níveis de conflito de papéis tanto no sentido família-trabalho como trabalho-família maior nas mulheres do que os homens (H1). 


\section{Género, conflito de papéis e seus antecedentes}

$\mathrm{Na}$ tentativa de melhor compreender os diversos tipos de relações trabalho-família, os estudos têm procurado identificar os determinantes do conflito ao nível das pressões de tempo, dos stressores e apoios dos domínios familiar e profissional, e do envolvimento da pessoa em cada um dos papéis (Adams, King, \& King, 1996; Aryee, Srinivas, \& Tan, 2005; Frone, et al. 1997). Apesar da investigação ter vindo a focar essencialmente o conflito do trabalho para a família, uma abordagem bidirecional que enfatize quer o impacto do desempenho do papel profissional no desempenho do papel familiar, quer o impacto do papel familiar no papel profissional permitirá esclarecer melhor as relações entre as duas esferas (Adams, et al., 1996; Frone et al., 1992a; Greenhaus \& Beutell, 1985). Contudo, estas duas direcções de conflito apresentam como vantagem o facto de poderem ser analisadas separadamente, dado que, como defendem Frone et al. (1992a), têm origem distinta: antecedentes familiares evidenciam o conflito da família para o trabalho, enquanto que os antecedentes profissionais são mais determinantes para o conflito do trabalho para a família. Para além disso, alguns estudos sugerem também que a importância destes antecedentes pode variar em função do género (Duxbury \& Higgins, 1991). A escassez de estudos empíricos nesse âmbito (ver Parasuraman \& Greenhaus, 2002) exige, contudo, a confirmação de tal previsão.

Em cada domínio (familiar ou profissional), os stressores parecem estar associados de forma mais intensa ao aumento do conflito, enquanto que os recursos individuais, familiares e profissionais, como o apoio obtido em cada um destes papéis ou a gratificação com o seu desempenho, parecem associados à sua redução e ao aumento do bem-estar individual (Hill, 2005).

$\mathrm{O}$ estudo aqui apresentado pretende contribuir para a caracterização do conflito de papéis em homens e mulheres de famílias portuguesas de duplo-emprego com filhos. Assumindo que o conflito pode ser bidirecional, serão primeiramente analisados os antecedentes profissionais do conflito trabalho-família. Num segundo momento, destacam-se os antecedentes familiares do conflito família-trabalho (figura 1). Será dada uma atenção particular às variações destas relações em função do género.

\section{Antecedentes do conflito trabalho-familia}

Como antecedentes do conflito trabalho-família privilegiaram-se os antecedentes do papel profissional, nomeadamente o stress e a satisfação com o papel profissional, o número de horas dispendidas neste papel e a percepção de apoio à família pela organização. 


\section{Stress Profissional}

A investigação evidencia que o stress associado à profissão é susceptível de provocar tensões no exercício concomitante de papéis e que estas tensões tendem a transferir-se para a vida familiar (Thompson, 1991; Wayne, Musisca, \& Fleeson, 2004). De facto, o stress profissional parece activar o conflito trabalho-família, tanto para os homens como para as mulheres (Byron, 2005), pelo que, actualmente, em Portugal, não se espera que os níveis de stress profissional sejam inferiores nas mulheres (H2). De facto, as actividades profissionais desenvolvidas pelas mulheres são bastante semelhantes às dos homens, já que trabalham essencialmente a tempo inteiro, com horários longos e não alteram as suas trajectórias profissionais com a maternidade (Torres, 2004). Contudo, na linha do que é defendido por alguns autores (Duxburry \& Higgins, 1991; Greenglass \& Devins, 1982), o seu peso preditivo no conflito trabalho-família poderá ser superior para as mulheres. Para elas, o desempenho do papel profissional pode colidir com o sua capacidade de cumprir com as tarefas familiares, o que poderá aumentar a percepção de conflitualidade entre papéis. De facto, continua a ser atribuído ao sexo feminino o papel familiar como o principal (Amâncio, 1994). Assim, espera-se que o stress profissional tenha um impacto superior na predição de conflito trabalho-família para as mulheres, em comparação com os homens (H3).

\section{Satisfação Profissional}

Ao contrário do stress, a satisfação profissional permitirá reduzir a conflitualidade, na medida em que poderá causar sentimentos positivos que atenuam a sobrecarga associada ao papel profissional (Kopelman, Greenhaus, \& Connolly, 1983). De facto, Kossek \& Ozeki (1998), numa revisão de estudos sobre conflito entre papéis, observaram uma relação negativa entre conflito e satisfação profissional. Contudo, não existem estudos que documentem diferenças de género perante os níveis de satisfação profissional entre homens e mulheres (H4). Na linha do que foi evidenciado por Kossek \& Ozeki (1998) e Stevens, Minnotte, \& Kiger (2004), relativamente ao impacto desta variável na predição de conflito, também não se esperam diferenças de género no impacto da satisfação profissional no conflito trabalho-família (H5).

\section{Número de horas de trabalho}

O número de horas despendidas no trabalho remunerado tem sido considerado como a variável chave na análise do conflito trabalho-família (Barnett, 1998; Carlson \& Kacmar, 2000; Frone et al. 1997a; Greenhaus \& Beutell, 1985). Assumindo que o tempo é um recurso limitado, quando os indivíduos despendem mais tempo para cumprir as responsabilidades associadas a um dos papéis, resta-lhes menos tempo para cumprir com as exigências do 
outro papel. Assim, um maior número de horas de trabalho tem sido apontado como uma das variáveis que mais contribui para a percepção de sobrecarga associada ao papel profissional (Kmec, 1999), o que explicaria a relação positiva entre o número de horas de trabalho pago e a tensão e conflito trabalho-família (Kmec, 1999). No entanto, resultados de outros estudos não evidenciam relações significativas entre essas variáveis (Barnett, 1998), o que parece indicar que os processos que ligam o número de horas de trabalho ao conflito entre a esfera profissional e familiar não têm sido ainda suficientemente explorados na literatura.

Estes resultados, aparentemente inconsistentes, poderão ser melhor compreendidos se considerarmos a interferência de outros aspectos da actividade profissional. Se os empregos que implicam um maior número de horas de trabalho são simultaneamente empregos com bons salários, mais regalias e que englobam actividades mais complexas e desafiantes, a satisfação profissional aumentará, compensando o efeito do tempo sobre o conflito. Para além destes factores, Barnett (1998) refere também que o facto de despender muitas horas no trabalho impede os indivíduos de investir noutras actividades potencialmente causadoras de stress, que poderiam ter um impacto negativo no seu bem-estar individual. Assim, quando os homens despendem maior número de horas em trabalho remunerado do que as suas companheiras, serão geralmente dispensados da maioria das tarefas em casa, assumidas por estas. Ora, prevemos que, na maioria dos casos, os homens passem mais horas na sua actividade profissional do que as mulheres (H6). Além disso, para as mulheres, as tarefas domésticas, pela sua natureza rotineira e o baixo nível de possibilidades de controlo, podem estar negativamente associadas ao bem-estar individual e anular o impacto eventualmente positivo de um número mais reduzido de horas de trabalho profissional. Assim, e pelos processos de compensação explicitados, espera-se que a relação entre as horas de trabalho profissional e o conflito trabalho-família seja diferente para homens e mulheres. Para os homens esta deverá ser uma relação negativa, enquanto que para as mulheres essa relação será anulada pela execução de tarefas domésticas, como exposto (H7).

Percepção de apoio à família na organização

O apoio dado pelas organizações para a conciliação de papéis (através da flexibilidade de horários, apoio por parte das chefias, apoio do supervisor directo) tem sido identificado como um contributo importante para que os indivíduos percepcionem menos conflito entre papéis (Anderson, Coffey, \& Byerly, 2002; Hill, 2005; Jacobs \& Gerson, 2004; Kossek, Noe, \& DeMarr, 1999). Uma vez que o meio profissional de mulheres e homens é idêntico, não se esperam diferenças de género na percepção de medidas de apoio à família no local de trabalho (H8). 
Contudo, dado que as mulheres são consideradas as principais responsáveis pela família e que os programas de apoio à família nos locais de trabalho parecem estar mais orientados para as mulheres (Hill, 2005), uma cultura profissional que tenta apoiar os trabalhadores na satisfação das necessidades familiares será um factor mais determinante para a redução do conflito trabalho-família das mulheres do que dos homens (H9).

\section{Antecedentes do conflito familia-trabalho}

Foram privilegiados como antecedentes do conflito família-trabalho, os stressores e recursos ao nível familiar, isto é, o stress familiar e a divisão do trabalho familiar e as suas variações em função do género.

\section{Stress Familiar}

A tensão percebida no âmbito do papel familiar, por exemplo tensão decorrente de problemas de relacionamento com os membros da família, está associada à percepção de conflito família-trabalho (Byron, 2005; Carlson, 1999; Frone et al., 1992a; Higgins \& Duxbury, 1992; Kopelman et al., 1983).

Os estudos que se debruçaram sobre as diferenças de género ao nível do stress familiar têm levado a resultados divergentes. Por um lado, dado que o papel tradicional feminino confere às mulheres uma maior responsabilidade sobre a esfera familiar, pode esperar-se que a sobrecarga familiar e parental seja superior para estas (Byron, 2005; Duxburry \& Higgins, 1991). Contudo, outros autores realçam que o poder preditivo do stress familiar no conflito não varia em função do género (Frone et al., 1992a).

Como o trabalho familiar é um elemento essencial dos papéis femininos prescritos na sociedade portuguesa (Wall, 2005), prevemos que as mulheres tenham níveis de stress familiar superior aos homens (H10) e que o stress familiar tenha um papel mais preponderante na predição de conflito família-trabalho nas mulheres do que nos homens (H11).

\section{Divisão do trabalho Familiar}

Os estudos sobre o uso do tempo relatam também que um maior dispêndio de horas em actividades familiares, como tarefas de cuidado dos filhos e tarefas domésticas, está relacionado com maiores percepções de conflito (Byron, 2005; Greenhaus \& Beutell, 1985; Grywacz \& Marks, 2000; Gutek et al., 1991), nomeadamente de conflito da família para o trabalho (Byron, 2005; Gutek et al., 1991). Quanto mais pequenos e dependentes forem os filhos, maior a percepção de conflito, em particular para a mãe (Grzywacz \& Marks, 2000; Jacobs \& Gerson, 2004). Com efeito, os filhos, em especial em idade pré-escolar, requerem mais atenção e exigem maior planeamento e organização do tempo por parte dos cuidadores. 
Figura 1: Antecedentes familiares e profissionais do conflito

\section{Papel Profissional}

Stress Profissional Satisfação Profissional

Percepção de apoio à família pela organização

Horas de trabalho profissional

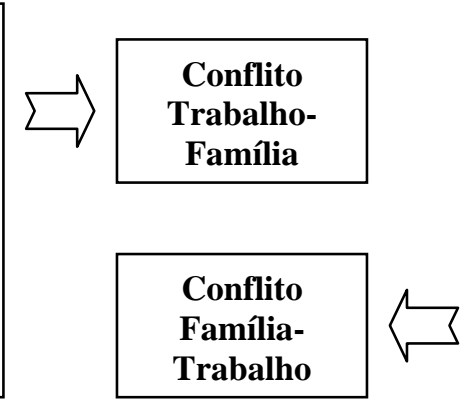

Papel Familiar

Stress Familiar

Divisão do Trabalho

Familiar:

- tarefas domésticas

- tarefas de repara-

ção/manutenção

- tarefas de cuidado

dos filhos

Os papéis tradicionais de género, prevalentes na sociedade portuguesa, permitem prever um maior nível de conflito família-trabalho nas mulheres. Além das mulheres serem responsáveis pela maior parte do trabalho familiar, o tipo de tarefas executadas por homens e mulheres é qualitativamente diferente. As mulheres são habitualmente encarregadas das tarefas que têm que ser feitas diariamente, que requerem mais tempo e que, sendo associadas ao cuidado dos filhos, não podem ser adiadas (Blair \& Lichter, 1991; Perista, 2002; Presser, 1994). As tarefas tradicionalmente masculinas, por sua vez, tendem a ser mais flexíveis em termos de tempo e frequência de realização; ocorrem maioritariamente fora de casa e encontram-se muitas vezes associadas a uma componente lúdica, como, por exemplo, tratar do carro, do jardim, reparar as avarias ou brincar com as crianças (Blair \& Lichter, 1991). Deste modo, espera-se que as mulheres desempenhem mais tarefas de cuidado dos filhos e tarefas domésticas e que os homens desempenhem mais tarefas de reparação (H12) e que as primeiras (tarefas domésticas e de cuidado dos filhos) contribuam para uma maior percepção de conflito família-trabalho nas mulheres do que nos homens (H13).

\section{Método}

\section{Amostra e Procedimento}

Como foi documentado por vários estudos, é nas famílias de duplo-emprego com filhos em idade pré-escolar que a questão da conciliação se coloca com maior pertinência. De facto, quando os pais exercem ambos uma actividade profissional, aqueles que têm filhos apresentam valores mais ele- 
vados de conflito profissional e familiar, maiores níveis de stress e menores níveis de bem-estar que os que não têm filhos. Neste sentido, para constituição da amostra foram definidos a priori um conjunto de critérios de selecção ${ }^{3}$ : ambos os elementos do casal deveriam viver juntos, exercer uma actividade profissional remunerada, trabalhando no mínimo 15 horas por semana e possuir pelo menos um filho com idade compreendida entre 1 e 5 anos. No caso de existirem irmãos, estes não deveriam ter mais do que 12 anos. Este último critério serviu o propósito de eliminar casais que possuíssem já uma longa experiência de conciliação.

Os casais foram contactados telefonicamente ou no decorrer de reuniões presenciais em creches e jardins-de-infância, bem como em organizações desportivas, em empresas, cursos de pós-graduação e via internet, de modo a abranger um leque mais diversificado de situações quanto ao nível sociocultural dos pais e ao modo de guarda das crianças. A maioria dos casais vivia no Norte e Centro do país. Nestes primeiros contactos, foram especificados quer os objectivos da investigação, quer as condições de participação.

A amostra portuguesa é assim composta por 492 sujeitos (246 casais) com idades compreendidas entre os 24 e os 56 anos de idade, com uma média de 35 anos. A maioria das famílias tem apenas uma criança (moda de filhos por casal=1). Apesar da diversidade de métodos de recolha da amostra utilizados, cerca de $60 \%$ dos indivíduos apresentam uma escolaridade acima do $12^{\circ}$ ano. Em média, os homens trabalham 53 horas/semana e as mulheres 45 horas/semana. Este cálculo incluiu o tempo de deslocação de e para o local de trabalho, bem como o trabalho profissional efectuado em casa.

\section{Instrumentos}

Todos os instrumentos ${ }^{4}$ usados neste estudo apresentavam afirmações relativamente às quais o sujeito teria de se situar numa escala do tipo Likert de 6 pontos, desde "aplica-se totalmente" a "não se aplica" ou em termos de frequência de "nunca" a "muitas vezes". A sua consistência interna é geralmente satisfatória.

Conflito Trabalho-Família: Esta escala é composta por dois itens que avaliam a interferência em termos de tempo e responsabilidades do domínio

\footnotetext{
${ }^{3}$ O presente estudo foi efectuado no quadro do Projecto Famwork: Vida Familiar e Profissional, Conflito e Sinergia, desenvolvido em parceria com nove grupos de trabalho de diferentes países da Europa (Alemanha, Áustria, Bélgica, Finlândia, França, Holanda, Itália, Portugal e Suíça).

${ }^{4}$ Os instrumentos foram desenvolvidos pelas equipas de investigação do projecto Famwork.
} 
profissional no domínio familiar. (Ex.: A minha actividade profissional impede-me de estar com a família o tempo que desejaria) $(\alpha=0,81)$.

Conflito Família-Trabalho: composta por dois itens que avaliam a interferência de tempo e comprometimento profissional nas responsabilidades familiares. (Ex.: As minhas obrigações familiares dificultam o cumprimento das minhas obrigações profissionais (por exemplo, pontualidade, rendimento diário, horas extraordinárias, etc.) $(\alpha=0,83)$.

Stress Profissional: composta por cinco itens que medem as reacções subjectivas dos participantes a condições potencialmente negativas do seu local de trabalho. Os participantes devem ponderar a frequência com que se sentem afectados pelos cinco factores. (Ex.: Com que frequência se sentiu afectado por trabalho cansativo.) $(\alpha=0,61)$.

Satisfação profissional: composta por três itens que medem a percepção de experiências positivas relativas ao papel profissional. (Ex.: Sinto-me realizado na minha actividade profissional.) $(\alpha=0,84)$.

Percepção subjectiva de apoio à família na organização: composta por cinco itens que procuram captar a percepção que o indivíduo tem acerca da flexibilidade existente no seu local de trabalho para o ajudar a lidar com os compromissos familiares. (Ex.: O meu superior/chefe mostra-se muito compreensivo em relação à minha situação familiar (por exemplo, na distribuição do trabalho, na marcação de férias, etc. $)(\alpha=0,70)$.

Horas de trabalho profissional: questão de resposta aberta onde os indivíduos indicam o número de horas semanais gastas com actividade profissional, considerando todo o tempo que é dispensado nessa actividade (no emprego, em casa e nas deslocações).

Stress familiar: composta por quatro itens que se referem a tensões associadas ao cumprimento do papel familiar, incluindo aspectos da relação pais-criança. (Ex.: Sobrecarregado devido a falta de tempo para relaxar e "desligar".) $(\alpha=0,71)$.

Divisão do trabalho familiar: composto por três itens analisados em separado que reflectem diferentes aspectos do trabalho familiar - tarefas domésticas, de manutenção/reparação e de cuidado dos fillhos. Em cada item, o indivíduo deverá indicar a quantidade de trabalho (doméstico, de reparação, com os filhos) por ele/ela efectuado.

\section{Procedimento de análise}

Numa primeira fase, foram analisadas as diferenças de género para cada uma das variáveis consideradas. Numa segunda fase, testaram-se as 
hipóteses relativas aos antecedentes do conflito ${ }^{5}$ trabalho-família (CTF) e do conflito família-trabalho (CFT). Para poder testar as nossas hipóteses, efectuaram-se análises separadamente por género.

\section{Resultados}

A observação da tabela 1 evidencia que, apesar dos indivíduos apresentarem valores mais elevados de conflito no sentido do trabalho para a família do que no sentido da família para o trabalho, os homens apresentam valores significativamente mais elevados de CTF que as mulheres $(\mathrm{t}$ $(490)=2,873 ; p=.004)$, enquanto que as mulheres têm valores mais elevados de CFT que os homens $(\mathrm{t}(490)=-3,580 ; \mathrm{p}<.001)$. Este resultado contraria parcialmente a nossa hipótese (H1), segundo a qual as mulheres sentiriam mais conflito em qualquer dos sentidos. Confirmando as hipóteses relativas à distribuição do trabalho profissional (H6), os homens trabalham em média mais nove horas por semana do que as mulheres $(\mathrm{t}(461,44)=6,011 ; \mathrm{p}<.001)$. No âmbito familiar, como previsto (H12), as mulheres desempenham significativamente mais tarefas familiares, nomeadamente tarefas domésticas $(\mathrm{t}$ $(490)=-15,883 ; \mathrm{p}<.001)$ e de cuidado dos filhos $(\mathrm{t}(448,872)=-16,725$; $\mathrm{p}<.001$ ), enquanto os homens desempenham maior número de tarefas de reparação $(\mathrm{t}(480,511)=11,218 ; \mathrm{p}<.001)$. Verifica-se ainda que as mulheres apresentam maiores índices de stress familiar do que os homens ( $\mathrm{t}(490)=$ -4,496; $<<.001$ ), confirmando também a nossa hipótese (H10).

Por último, verificou-se que não existem diferenças de género na percepção de sobrecarga com a actividade profissional, tal como previsto na hipótese $(\mathrm{H} 2)(\mathrm{t}(490)=, 511 ; \mathrm{p}=.609)$ e que o apoio informal dado à vida familiar pela organização é moderado $(x=3.65 ; 3.51)$ e percebido de forma idêntica por homens e mulheres $(\mathrm{t}(490)=1,398 ; \mathrm{p}=.163)$, o que permitiu confirmar a hipótese inicial (H8). No entanto, os homens apresentam maiores índices de satisfação com a actividade profissional que as mulheres $(\mathrm{t}(481)=-2,393 ; \mathrm{p}=.017)$, o que contraria a hipótese $(\mathrm{H} 4)$.

\footnotetext{
${ }^{5}$ Será utilizado o teste $\mathrm{T}$ de Student para avaliar as diferenças de género e as análises de regressões lineares múltiplas com o método "stepwise"para avaliar os antecedentes do conflito que implica que, na equação de regressão, entram sequencialmente as variáveis com maior poder preditivo até aquelas com menor poder preditivo.As variáveis dependentes nessas análises de regressão foram o conflito trabalho-família (CTF) e o conflito família-trabalho (CFT)
} 
Tabela 1: Média e desvio-padrão das variáveis em estudo

\begin{tabular}{|c|c|c|c|c|}
\hline \multirow[b]{2}{*}{ Variáveis } & \multicolumn{2}{|c|}{ Homens $(n=246)$} & \multicolumn{2}{|c|}{ Mulheres $(n=246)$} \\
\hline & $M$ & $D P$ & $M$ & $D P$ \\
\hline 1. Conflito Trabalho-Família** & 3,70 & 1,46 & 3,32 & 1,41 \\
\hline 2. Conflito Família-Trabalho*** & 2,35 & 1,29 & 2,77 & 1,33 \\
\hline 3. Stress Profissional & 3,70 & 0,83 & 3,66 & 0,92 \\
\hline 4. Satisfação Profissional * & 4,43 & 0,90 & 4,23 & 0,89 \\
\hline $\begin{array}{l}\text { 5. Percepção de apoio à família dado pela } \\
\text { organização }\end{array}$ & 3,65 & 1,10 & 3,51 & 1,13 \\
\hline 6. Horas de trabalho profissional $(\mathrm{h}) * * *$ & 53,14 & 16,80 & 44,98 & 13,04 \\
\hline 7. Stress Familiar $* * *$ & 2,77 & 0,90 & 3,14 & 0,92 \\
\hline $\begin{array}{l}\text { 8. Divisão do trabalho familiar: tarefas } \\
\text { domésticas } * * *\end{array}$ & 3,08 & 1,13 & 4,66 & 1,08 \\
\hline $\begin{array}{l}\text { 9. Divisão do trabalho familiar: tarefas } \\
\text { manutenção/ reparação*** }\end{array}$ & 4,47 & 1,07 & 3,29 & 1,24 \\
\hline $\begin{array}{l}\text { 10. Divisão do trabalho familiar: tarefas } \\
\text { cuidado dos filhos*** }\end{array}$ & 3,63 & 1,02 & 4,98 & 0,75 \\
\hline
\end{tabular}

Nota: ${ }^{*} \mathrm{p}<.05,{ }^{* *} \mathrm{p}<.01,{ }^{* * *} \mathrm{p}<.001$

Nas tabelas 2 e 3 apresentam-se os resultados dos modelos de regressão para o CTF e o CFT, respectivamente. Além dos valores do coeficiente de determinação, só se apresentam os valores preditivos ( $\beta$ estandardizados) das variáveis que contribuíram significativamente para a variação da variável dependente considerada. Os resultados são apresentados para homens e mulheres separadamente.

Dos preditores do CTF (tabela 2) para os homens, o primeiro preditor é o número de horas na actividade profissional, seguido do stress familiar. O modelo de regressão feminino é idêntico ao masculino, contudo o preditor mais importante do CTF é o stress profissional, seguido das horas de trabalho profissional. O modelo de regressão masculino conta com duas variáveis explicativas, sendo a variância total explicada de cerca de $15 \%\left(\mathrm{R}=.39 ; \mathrm{R}^{2}\right.$ $=.15)$, sendo este modelo significativo $(\mathrm{F}(2,245)=21,13 ; \mathrm{p}<.001)$. O modelo de regressão feminino conta também com duas variáveis explicativas, sendo a variância total explicada de cerca de $18 \%\left(R=.42 ; R^{2}=.18\right)$, sendo este 
modelo também significativo $(\mathrm{F}(2,245)=26,28 ; \mathrm{p}<.001)$. Relativamente às hipóteses previstas, podemos verificar que o facto do stress profissional se ter mostrado um preditor mais importante para as mulheres ( $\beta$ superior) vai de encontro ao previsto (H3). No entanto, o facto do número de horas de trabalho ser igualmente importante na predição de CTF para homens e mulheres contraria a nossa hipótese (H7). Adicionalmente, esperava-se que as medidas de apoio à família e a satisfação profissional tivessem um impacto no conflito trabalho-família, o que não se verificou (H5 e H9 infirmadas).

Tabela 2: Análise da regressão múltipla para a VD: conflito trabalho-família (coeficientes de regressão estandardizados)

\begin{tabular}{lll}
\hline Variáveis & $\begin{array}{l}\text { Homens } \\
(\mathrm{n}=246)\end{array}$ & $\begin{array}{l}\text { Mulheres } \\
(\mathrm{n}=246)\end{array}$ \\
\hline 1. Stress Profissional & $.18^{* *}$ & $.30^{* * *}$ \\
2. Satisfação Profissional & & \\
3. Percepção de apoio à família dado pela organização & & \\
4. Horas de trabalho profissional & $.33^{* * *}$ & $.22^{* * *}$ \\
\hline $\mathrm{R}^{2}$ ajustado & $.15^{* * *}$ & $.18^{* * *}$ \\
\hline Nota: * $\mathrm{p}<.05 ; * * \mathrm{p}<.01 ; * * * \mathrm{p}<.001$. & &
\end{tabular}

Quanto aos preditores do CFT (tabela 3), verifica-se que, para os homens, o preditor mais importante é o stress familiar, seguido da quantidade de tarefas de cuidado das crianças realizadas. Deste modo, quanto maior o índice de stress familiar e a quantidade de tarefas desempenhadas, maior o CFT. Para as mulheres, mantém-se como primeiro preditor o índice de stress familiar, seguindo-se a quantidade de trabalho doméstico realizado. Assim, para as mulheres, quanto maior for o índice de tensão na família e quanto menos tarefas domésticas realizarem, maior será a percepção de CFT. O modelo de regressão masculino conta com duas variáveis explicativas, sendo a variância total explicada de cerca de $14 \%\left(\mathrm{R}=.37 ; \mathrm{R}^{2}=.14\right)$; o modelo é significativo $(\mathrm{F}(2,245)=18,91 ; \mathrm{p}<.001)$. $\mathrm{O}$ modelo de regressão feminino, também é significativo $(\mathrm{F}(2,245)=7,38 ; \mathrm{p}<.01)$, conta igualmente com duas variáveis explicativas que contribuem com $6 \%$ de variância total explicada $\left(\mathrm{R}=.24 ; \mathrm{R}^{2}=.06\right)$. 
Tabela 3: Análise da regressão múltipla para a VD: conflito família-trabalho (coeficientes de regressão estandardizados)

\begin{tabular}{lll}
\hline Variáveis & $\begin{array}{c}\text { Homens } \\
(\mathrm{n}=246)\end{array}$ & $\begin{array}{c}\text { Mulheres } \\
(\mathrm{n}=246)\end{array}$ \\
\hline $\begin{array}{l}\text { 1. Stress Familiar } \\
\text { 2. Divisão do trabalho familiar: tarefas domésticas }\end{array}$ & $.16^{* *}$ \\
$\begin{array}{l}\text { 3. Divisão do trabalho familiar: tarefas manuten- } \\
\text { ção/reparação }\end{array}$ & \\
$\begin{array}{l}\text { 4. Divisão do trabalho familiar: tarefas cuidado dos } \\
\text { filhos }\end{array}$ & $.17^{* *}$ \\
\hline $\mathrm{R}^{2}$ ajustado & $.14^{* * *}$ & \\
\hline
\end{tabular}

Nota:* $\mathrm{p}<.05 ; * * \mathrm{p}<.01 ; * * * \mathrm{p}<.001$.

Relativamente às hipóteses postuladas, verificamos algumas divergências face ao previsto. O stress familiar revelou-se um preditor importante quer para homens, quer para mulheres, no entanto o seu papel é ligeiramente superior nos homens ( $\beta$ superior) (H11). Quanto às tarefas familiares, verificamos que, de acordo com o previsto, a quantidade de tarefas domésticas realizadas é preditora de CFT para as mulheres, contudo trata-se de uma relação negativa, o que contraria a nossa hipótese (H13). Por fim, as tarefas de cuidado dos filhos, contrariamente ao previsto, mostraram-se preditoras de CFT somente para os homens (H13).

\section{Discussão dos resultados}

$\mathrm{Na}$ análise dos resultados começamos por destacar que, contrariamente ao esperado, as mulheres sentem mais conflito que os homens unicamente na direcção família-trabalho; enquanto os homens sentem mais conflito trabalho-família. Este dado sublinha a força dos papéis de género tradicionais, que atribuem aos homens, como principal fonte de identificação, o domínio profissional e às mulheres o domínio familiar. Assim, as exigências do domínio pelo qual cada um se sente mais responsável entram em conflito com o domínio que reflecte menos os papéis prescritos para cada sexo. Contudo, tanto para homens como para mulheres, o número de horas no exercício da actividade profissional é também um preditor importante do conflito 
trabalho-família, sendo mesmo o preditor mais importante para os homens. Estes resultados inscrevem-se na linha de outros que tinham constatado que um elevado número de horas passadas no exercício do papel profissional era susceptível de gerar tensões nos indivíduos, levando à ocorrência de conflito entre o trabalho e a família (Kmec, 1999; Noor, 2003). De facto, um número elevado de horas profissionais origina um desgaste físico e emocional que associado à redução da disponibilidade temporal, condiciona o investimento no papel familiar (Carlson \& Kacmar, 2000; Frone et al., 1997). Adicionalmente, e também consistente com a literatura, o stress profissional é um importante preditor do conflito trabalho-família (Aryee, et al., 2005; Frone, et al., 1997; Greenhaus \& Beutell, 1985; Grzywacz \& Marks, 2000). Este resultado parece indicar que o desgaste associado ao papel profissional poderá levar a níveis mais baixos de energia e disponibilidade para o envolvimento com o papel familiar, podendo assim contribuir para que os indivíduos sintam que este entra em conflito com as exigências familiares. Apesar de não existirem diferenças de género na percepção de stress profissional, o stress é melhor preditor do conflito nas mulheres. Sendo consideradas as principais responsáveis da família na sociedade portuguesa, o facto das mulheres, depois do seu dia de trabalho, terem, habitualmente, de enfrentar uma segunda jornada de trabalho, também exigente e indispensável ao bom funcionamento familiar, pode torná-las mais conscientes do impacto do stress profissional sobre a vida familiar.

Contrariamente ao esperado, a influência da satisfação profissional na redução da percepção do conflito não se verificou (Greenhaus \& Powell, 2006; Voydanoff, 2002). Segundo Greenhaus \& Powell (2006), seria de esperar que a satisfação obtida no desempenho do papel profissional minimizasse os efeitos negativos da interferência deste no papel familiar. Contudo, como destaca Voydanoff $(2004,2005)$, as exigências prevalecem sobre os recursos na determinação do conflito. Assim, a percepção de conflito parece derivar menos da existência de recursos materiais ou psicológicos (como satisfação profissional ou apoio da organização), do que das exigências associadas ao papel. Os resultados encontrados parecem demonstrar efectivamente que, nem os recursos de apoio à família disponibilizados pela organização nem a satisfação profissional reduzem o conflito trabalho-família, indo ao encontro da proposta de Voydanoff $(2004,2005)$. Contudo a ausência de efeito das medidas promovidas para apoiar a família pode também ser devida à sua inadequação face às necessidades dos indivíduos, $o$ que poderá originar que o sistema de apoio não seja percepcionado como útil pelos seus potenciais beneficiários. De facto, a mera oferta da organização de medidas de apoio à família, não implica que estas sejam usadas pelos trabalhadores (Guerreiro \& Abrantes, 2007). Alguns autores apontam para barreiras de natureza social e organizacional que levam a que os programas e 
apoios fornecidos não tenham a eficácia desejada; destacam-se as crenças acerca dos papéis de género, definições tradicionais do que é um bom trabalhador, definições de sucesso profissional, entre outras (Allen, 2001; Kossek, Barber, \& Winters, 1999; Thompson, Beauvais, \& Lyness, 1999). Além disso, no contexto nacional, as medidas disponibilizadas pelas organizações são avaliadas como escassas, tendo os indivíduos de encontrar soluções de carácter privado para lidar com a maioria das questões familiares (Guerreiro \& Abrantes, 2007).

$\mathrm{Na}$ análise do conflito família-trabalho, verifica-se que, tanto para homens como para mulheres, o stress familiar é um bom preditor desta forma de conflito, situando-se estes resultados na linha do que foi encontrado por outros autores (Byron, 2005; Carlson, 1999; Frone et al., 1992a; Higgins \& Duxbury, 1992). Contudo, este stress familiar não pode ser atribuído a sobrecarga em termos de trabalho doméstico. Aliás, para as mulheres, verifica-se que um menor desempenho das tarefas domésticas está associado a maiores índices de conflito, contrariamente ao que uma abordagem racional da quantidade de trabalho faria prever. Isto é, ao desempenhar mais tarefas domésticas, as mulheres não sentem maior conflito entre a família e o trabalho, mas, pelo contrário, sentem menos conflito. Este resultado pode ser explicado pela hipótese relativa ao reforço da identidade de género que ocorre quando homens e mulheres desempenham tarefas específicas e tradicionais do seu próprio sexo (Brines, 1994; West \& Zimmerman, 1987), limitando, deste modo, o impacto negativo das tarefas domésticas na percepção de conflito.

No caso dos homens, quanto mais tarefas de cuidado aos filhos desempenhadas, maior o conflito família-trabalho experimentado, corroborando o resultado evidenciado por Grywacz \& Marks (2000). O estudo de Coltrane (2000) revelou também que o envolvimento dos homens no papel parental, apesar de promover activamente sentimentos de bem-estar subjectivo, traduz-se, objectivamente, num menor investimento no papel profissional. Ora, actualmente, é esperada uma participação masculina activa no cuidado das crianças, desde o brincar ao cuidar, ao alimentar e ajudar nas tarefas de escola (Jacobs \& Gerson 2004; Poeschl, 2000). Assim, o intenso envolvimento com as crianças que se espera dos pais pode tornar a participação e o envolvimento no trabalho mais problemático, contribuindo para o conflito família-trabalho.

Como se pôde verificar, a percepção de sobrecarga no âmbito familiar, bem como uma participação mais activa no cuidado dos filhos mostraram-se melhores preditores ( $\beta$ superior) da percepção de conflito dos homens do que das mulheres. Aliás, para as mulheres, maior participação nas tarefas domésticas contribui para menor conflito. Os resultados permitem-nos evidenciar que, na linha de Amâncio (1994), as prescrições sociais internalizadas por homens e mulheres moldam os comportamentos dos indivíduos através das 
expectativas que eles próprios e os outros possuem e podem penalizar os comportamentos que violam as expectativas sociais de género. Por via da socialização, os homens tendem a valorizar e identificar-se mais com o papel profissional e as mulheres com o papel familiar. Assim, segundo Gutek et al. (1991), um maior envolvimento num papel "adequado" ao seu próprio sexo (trabalho famíliar no caso das mulheres e trabalho profissional no caso dos homens) não é visto como uma imposição, enquanto que mais horas ou envolvimento num domínio associado ao outro sexo poderão ser percebidas como tal. Uma vez que o trabalho familiar representa o domínio de responsabilidade tradicional das mulheres, estas não percepcionam as maiores exigências familiares como uma imposição mas como um dever assumido, pelo que poderão ter um menor impacto no conflito do domínio familiar para o domínio profissional. Pelo contrário, quando se desviam das normas internalizadas, homens e mulheres poderão sentir desconforto e/ou sofrer sanções externas na forma de desaprovação por parte dos outros significativos. Esta explicação serve também o caso dos homens, na medida em que uma maior participação no cuidado dos filhos leva a uma maior percepção de conflito, dado que executam um papel não tradicional que pode ser percepcionado por eles como uma imposição (Kroska, 2003).

\section{Conclusão e implicações}

Em suma, o conflito entre papéis é um problema que se coloca tanto às mulheres como aos homens portugueses, embora com contornos bastante diferenciados. Os resultados encontrados permitem evidenciar que tanto o stress profissional como horários de trabalho muito extensos activam formas de conflito entre trabalho e a família, com expressão diferenciada para homens e mulheres. Conforme destacámos, o papel das medidas de apoio à família deve ter em consideração este aspecto, devendo também ser ajustado, na medida do possível, aos potenciais beneficiários destas medidas. Importa também referir que o stress familiar e as tarefas domésticas contribuem para o conflito família-trabalho. Se, por um lado, este estudo corrobora a ideia de que o não cumprimento adequado das tarefas "femininas" por parte das mulheres activa a sua percepção de conflito de papéis, não é de menosprezar a importância destes factores para os homens. Este parece ser um dos aspectos mais relevantes do presente trabalho, na medida em que contribui para que a análise do conflito de papéis seja equacionada na especificidade de cada género.

Apesar do contributo deste estudo para análise das semelhanças e diferenças de género na análise do conflito de papéis em famílias portuguesas, sugerem-se alguns aspectos a explorar em futuros estudos. Ao nível concep- 
tual sugere-se uma análise mais aprofundada do modelo desenvolvido por Voydanoff (2004; 2005), que destaca o papel dos stressores, em detrimento dos recursos na percepção de conflito. Adicionalmente, um modelo mais completo que permita analisar para além de antecedentes do conflito, os seus efeitos ao nível individual, familiar e organizacional poderá também contribuir para uma análise detalhada dos processos subjacentes à formação do conflito de papéis. Um outro aspecto a contemplar em estudos futuros refere-se a uma análise mais detalhada do papel das medidas de apoio à família no processo de conflito, nomeadamente tipo de apoios disponibilizados e uso efectivo dos mesmos pelos indivíduos.

Ao nível metodológico, a amostra estudada é de conveniência e como tal os resultados obtidos não podem ser generalizados a outros grupos, nomeadamente de nível socioeconómico mais baixo. Para além disto, este estudo não permite indicar uma possível direcção de causalidade nos efeitos entre variáveis, dada a natureza dos dados ser correlacional. Estudos futuros efectuados com dados longitudinais poderão colmatar esta limitação.

Não obstante as limitações apontadas, este estudo permitiu uma abordagem integrada do conflito inter-papéis (trabalho-família e família-trabalho) num grupo de famílias sujeito a desafios concretos (famílias de duplo-emprego), incluindo as especificidades de homens e mulheres.

\section{Referências}

Adams, G., King, L. \& King, D. (1996). Relationships of job and family involvement, family social support and work-family conflict with job and life satisfaction. Journal of Applied Psychology, 8 (4) 411-420.

Allen, T. D. (2001). Family-supportive work environments: The role of organizational perceptions. Journal of Vocational Behavior, 58, 414-435.

Almeida, D. M., Wethington, E., \& Chandler, A L. (1999). Daily transmission of tensions between marital dyads and parent-child dyads. Journal of Marriage and the Family, 61, 49-61

Amâncio, L. (1994). Masculino e feminino. A construção social da diferença. Porto: Afrontamento

Anderson, S. E., Coffey, B. S., \& Byerly, R. T. (2002). Formal Organizational Initiatives and Informal Workplace Practices: Links to Work-Family Conflict and Job-Related Outcomes. Journal of Management, 28, 787-810.

Aryee, S, Srinivas, E., \& Tan, H. (2005). Rhythms of life: Antecedents and outcomes of work-family balance in employed parents. Journal of Applied Psychology, 90 (1) 132-146.

Barnett, R. (1998). Toward a review and reconceptualization of the work/family literature. Genetic, Social \& General Psychology Monographs, 124 (2), 125-153 . 
Blair, S., \& Lichter, D. (1991). Measuring the division of household labor: Gender segregation of housework among American couples. Journal of Family Issues, 12, 91-113.

Brines, J. (1994). Economic dependency, gender and the division of labor at home. American Journal of Sociology, 100 (3), 652-688.

Byron, K. (2005). A meta-analytic review of work-family conflict and its antecedents. Journal of Vocational Behavior, 67, 169-198.

Cabral-Cardoso, C. (2003). A igualdade de oportunidades entre homens e mulheres em contexto empresarial. Braga: Escola de Gestão da Universidade do Minho.

Carlson, D. (1999). Personality and Role Variables as predictors of three forms of work-family conflict. Journal of Vocational Behaviour, 55, 236-253

Carlson, D., \& Kacmar, K. (2000). Construction and initial validation of a multidimensional measure of work-family conflict. Journal of Vocational Behavior, $56,249-276$.

Coltrane, S. (2000). Research on household labor: Modeling and measuring the social embeddedness of routine family work. Journal of Marriage and the Family, 62, 1208-1233.

Duxbury, L., \& Higgins, C. (1991). Gender differences in work-family conflict. Journal of Applied Psychology, 76 (1), 60-74.

Edwards, J., \& Rothbard, N. (2000). Mechanisms linking work and family: Clarifying the relationships between work and family constructs. Academy of Management Review, 25 (1), 178-199.

Fontaine, A. M., Andrade, C., Matias, M., Gato, J., \& Mendonça, M. (2007). Family and work division in dual earner families in Portugal. In I. Crespi (Ed), Gender mainstreaming and family policy in Europe: perspectives, research and debates (pp. 167-198). Macerata: EUM.

Franks, S. (1999). Having none of it: Women, men and future of work. London: Granta Publications.

Frone, M., Russell, M., \& Cooper, M. (1992a). Antecedents and outcomes of work-family conflict: testing a model of the work-family interface. Journal of Applied Psychology, 77 (1), 65-78.

Frone, M., Russell, M., \& Cooper, M. (1992b). Prevalence of work-family conflict: are work and family boundaries asymmetrically permeable? Journal of Organizational Behavior, 13, 723-729.

Frone, M., Yardley, J., \& Markel, K. (1997). Developing and testing an integrative model of the work-family interface. Journal of Vocational Behavior, 50 (2), 145-167.

Gianakos, I. (2000). Gender roles and coping with work stress. Sex roles, 42, 1059-1079 .

Greenglass, E. R., \& Devins, R. (1982). Factors related to marriage and career plans in unmarried women. Sex Roles, 8, 57-71.

Greenhaus, J., \& Beutell, N. (1985). Sources of conflict between work and family roles. Academy of Management Review, 10 (1), 76-88. 
Greenhaus, J., \& Powell, G. (2003). When work and family collide: Decide between competing role demands. Organizational Behavior and Human Decision Processes, 90, 291-303.

Greenhaus, J., \& Powell, G. (2006). When work and family are allies: A theory of work-family enrichment. Academy of Management Review, 31 (1), 72-92.

Grzywacz, J., \& Bass, B. (2003). Work, family and mental health: Testing different models of work-family fit. Journal of Marriage and Family, 65, 248-262.

Grzywacz, J., \& Marks, N. (2000). Reconceptualizing the work-family interface: An ecological perspective on the correlates of positive and negative spillover between work and family. Journal of Occupational Health Psychology, 5 (1), 111-126.

Guerreiro, M., \& Abrantes, P. (2007). Transições incertas: Os jovens perante o trabalho e a familia. Lisboa: CITE.

Gutek, B., Searle, S., \& Klepa, L. (1991). Rational versus gender role explanations for work-family conflict. Journal of Applied Psychology, 76 (4), 560-568.

Higgins, C., \& Duxbury, L. (1992).Work-family conflict: A comparison of dual-career and traditional-career men. Journal of Organizational Behaviour, 13, $389-411$.

Hill, J. (2005). Work-Family facilitation and conflict, working fathers and mothers, work-family stressors and support. Journal of Family Issues, 26 (6), 793-819.

Hughes, D., \& Galinsky, E. (1988). Balancing work and family lives: Research and corporate applications. In A. E. Gottfried \& A. W. Gottfried (Eds), Maternal employment and children's development (pp. 233-268). New York: Plenum.

INE (2002). Inquérito ao emprego, Lisboa (Portugal).

INE (2004). Indicadores estatísticos gerais: estatísticas do emprego - III ${ }^{\circ}$ trimestre 2004, Lisboa (Portugal).

Ingersoll-Dayton, B., Neal, M., \& Hammer, L. (2001). Aging parents helping adult children: The experience of the sandwiched generation. Family Relations, 50, 262-271.

Jacobs, J. A., \& Gerson, K. (2004). The time divide: Work, family and gender inequality. Cambridge: Harvard University Press.

Kmec, J. (1999). Multiple aspects of work-family conflict. Sociological Focus, 32 (3), 265-285.

Kopelman, R., Greenhaus, J., \& Connolly, T. (1983). A model of work, family and interrole conflict: A construct validation study. Organizational Behavior \& Human Performance, 32 (2), 198-215.

Kossek, E., \& Ozeki, C. (1998). Work-family conflict, policies and the job-life satisfaction relationship: A review and directions for organizational behaviour-human resources research. Journal of Applied Psychology, 83 (2), 139-149

Kossek, E. E., Barber, A. E., \& Winters, D. (1999). Using flexible schedules in the managerial world: The power of peers. Human Resource Management, 38 (1), 33-46.

Kossek, E. E., Noe, R. A., \& DeMarr, B. J. (1999). Work-Family role synthesis: Individual and organizational determinants. The International Journal of Conflict Management, 10, 102-129. 
Kroska, A. (2003). Investigating gender differences in the meaning of household chores and childcare. Journal of Marriage and Family, 65 (2), 456-473.

Major, B. (1993). Gender, entitlement and the distribution of family labor. Journal of Social Issues, 49, 141-159.

Marshall, N., \& Barnett, R. (1993).Work-family strains and gains among two-earner couples.Journal of Community Psychology, 21, 64-78.

Noor, N. (2003). Work - and family related variables, work-family conflict and women's well-being: Some observations. Community, Work and Family, 6 (3), 297-319

O’Neil, R., Greenberg, E., \& Marks, S. (1994). Patterns of commitment to work and parenting: Implications for role strain - Comment/reply. Journal of Marriage and the Family, 56, 101-110.

Parasuraman, S., \& Greenhaus, J. (2002). Toward reducing some critical gaps in work-family research. Human Resource Management Review, 12, 299-312.

Perista, H. (2002). Género e trabalho não pago: Os tempos das mulheres e os tempos dos homens. Análise Social, 37 (163), 447-474.

Peterson, R. R., \& Gerson, K. (1993). A social-structural explanation of men's and women's domestic responsibility: A reply to Hawkins and Olsen. Journal of Marriage \& Family, 55, 508-510.

Poeschl. G. (2000). Trabalho doméstico e poder familiar: práticas, normas e ideais. Análise Social, 35 (156), 695-719.

Presser, H. (1994).Employment schedules among dual-earner spouses and the division of household labor by gender. American Sociological Review, 59, 348-364 .

Rachlin, V. C. (1987). Fair versus equal role relations in dual-career and dual-earner families: Implications for family interventions. Family Relations, 36, 187-192.

Stevens, D., Minnotte, K., \& Kiger, G. (2004). Differences in work to family and family to work spillover among professional and non-professional workers. Sociological Spectrum, 24, 535-551.

Stier, H., \& Lewin-Epstein.(2000). Woman's part-time employment and gender inequality in the family. Journal of Family Issues, 21, 390-410.

Thompson, L. (1991). Family work: Women's sense of fairness. Journal of Family Issues, 12, 81-196.

Thompson, C. A., Beauvais, L. L., \& Lyness, K. S. (1999). When work-family benefits are not enough: The influence of work-family culture on benefit utilization, organizational attachment, and work-family conflict. Journal of Vocational Behavior, 54, 392-415.

Torres, A. (2004). Vida conjugal e trabalho: Uma perspectiva sociológica. Oeiras: Celta Editora.

Vicente, A. (1998). As mulheres em Portugal na transição do milénio: Valores, vivências, poderes nas relações sociais entre os dois sexos. Lisboa: Multinova.

Voydanoff, P. (2002). Linkages between the work family interface and work, family and individual outcomes: An integrative model. Journal of Family Issues, 23, (1), 138-164. 
Voydanoff, P. (2004). Implications of work and community demands and resources for work-to-family conflict and facilitation. Journal of Occupational Health Psychology, 9 (4), 275-285

Voydanoff, P. (2005). The differential salience of family and community demands and resources for family to work conflict and facilitation. Journal of Family and Economic Issues, 26 (3), 395-417

Wall, K. (2005). Famílias em Portugal: Percursos, interacções, redes sociais. Lisboa: Imprensa de Ciências Sociais.

Wayne, J., Musisca, N., \& Fleeson, W. (2004). Considering the role of personality in the work-family experience: Relationships of the big five to work-family conflict and facilitation. Journal of Vocational Behaviour, 64, 108-130.

West, C., \& Zimmerman, D. (1987). Doing gender. Gender \& Society, 1 (2), 125 -151 .

Zimmerman, T., Haddock, S., Current, L., \& Ziemba, S. (2003). Intimate partnership: Foundation to the successful balance of family and work. The American Journal of Family Therapy, 31, 107-124. 